\title{
Article
}

\section{Tourists' perceptions regarding the use of anthropomorphic robots in tourism and hospitality}

Christou, Prokopis, Simillidou, Aspasia and Stylianou, Maria C. Available at http://clok.uclan.ac.uk/35303/

Christou, Prokopis, Simillidou, Aspasia and Stylianou, Maria C. (2020) Tourists' perceptions regarding the use of anthropomorphic robots in tourism and hospitality. International Journal of Contemporary Hospitality Management . ISSN 0959-6119

It is advisable to refer to the publisher's version if you intend to cite from the work. http://dx.doi.org/10.1108/JJCHM-05-2020-0423

For more information about UCLan's research in this area go to http://www.uclan.ac.uk/researchgroups/ and search for <name of research Group>.

For information about Research generally at UCLan please go to http://www.uclan.ac.uk/research/

All outputs in CLoK are protected by Intellectual Property Rights law, including Copyright law. Copyright, IPR and Moral Rights for the works on this site are retained by the individual authors and/or other copyright owners. Terms and conditions for use of this material are defined in the policies page.

\section{CLoK}

Central Lancashire online Knowledge www.clok.uclan.ac.uk

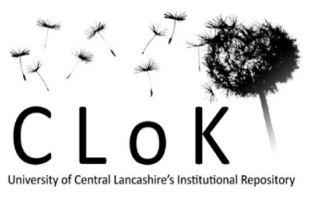




\title{
Tourists' perceptions on the use of anthropomorphic robots in tourism and hospitality
}

\begin{abstract}
Purpose

Service organizations rushed to deploy robots to serve people in quarantine amidst the coronavirus outbreak igniting once again the ongoing dispute regarding robots in tourism. The study's aim is to investigate perceptions of tourists over the use of robots and more specifically anthropomorphic robots in the tourism domain.
\end{abstract}

\section{Design/methodology/approach}

A qualitative inquiry was used to delve deep into the issue of tourists' perceptions regarding the usage of anthropomorphic robots in tourism, with a total number of 78 interviews with tourists being retained in the study.

\section{Findings}

The findings reveal that tourists favour the use of anthropomorphic robots as opposed to any other type of robot. The use of anthropomorphic robots in tourism may result in an overall enhanced experiential value. Even so, frustration, sadness and disappointment vis-à-vis the use of robots in a human-driven industry were also expressed by informants.

\section{Implications}

A conceptual continuum of tourists' perceptions and concerns over the use of robots is presented that can guide future studies. Tourism stakeholders may look at the possibility of incorporating carefully designed anthropomorphic robots in key service positions, yet should not give the impression that robots are replacing the human face of the organization.

\section{Originality}

Tourism organizations that make use of robots carry the risk of being perceived as non-anthropocentric. This leads to the conclusion that anthropomorphism could be used but should not replace the sector's anthropocentrism. The study conveys tourists' concerns over technological (robot) determinism.

Keywords: Anthropomorphism; human-like robots; androids; tourist perceptions; technology. 


\section{Introduction}

Amidst fears at the start of the coronavirus outbreak organizations rushed to deploy robots to serve customers, such as "Little Peanut" (Cuthbertson, 2020) who delivered food to people in quarantine at a hotel in Hangzhou. The use of automation technology and robots, particularly in services, became the epicentre of discussion for governments, organizations and entrepreneurs. Though tourism declined to a virtual standstill during that period, debates over the use of such technology once more sparked into life, and centred on the sector's highly human-type interaction and experiential nature.

As Neuhofer et al. (2014) rather appropriately positioned, the essence of the tourism industry is experiences. Superior customer experiences are essential in securing loyalty (Kandampully et al., 2018) while technological impacts on experiences is well-acknowledged. Examples include anything from information technology to augmented reality systems. Studies have investigated the role, importance or implication of technology, both in tourism (Tussyadiah et al., 2018; Huang et al., 2016) and the hospitality industry (Cha, 2020; Shin and Jeong, 2020, Ivanov and Webster, 2019; Okumus, 2013). Despite the challenges associated with its implementation, the impact of technology in the realm of the tourism is a well-examined topic and the technology that is used is often praised. Tourism and hospitality organizations began to adopt artificial intelligence prior to the coronavirus period, in the form of robots (Zhu and Chang, 2020). The study of Tussyadiah et al. (2018) found that technology embodiment definitely affects the enjoyment, as well as enhancing the experience of tourism attractions. Of course, this does not lead to the conclusion that the use of robots in tourism is necessarily linked to pleasant experiences. The study of Tung and Au (2018) found that while robots were used in the hospitality industry with the intention to enhance user experiences, guests reported several limitations such as their language ability. This led to negative customer feelings, particularly frustration and disappointment. Arguably, the task of delivering pleasant experiences becomes extremely challenging within a sector that supposedly relies on human interactions yet calls on its customers to interact with machines, some of which resembling humans. Indeed, robots are increasingly being designed as anthropomorphic by resembling human shapes and faces. Even so, a number of researchers call for further research regarding robots in the hospitality and tourism domain (Cha, 2020; Law et al., 2019; Tung and Law, 2017). Such research can be of importance at current times when hospitality managers are urged to build quality relationships with their customers (Law et al., 2018) while being aware of guests' feelings of discomfort when they are asked to interact with robots (Tung and $\mathrm{Au}, 2018$ ). This does not imply that research has not been channelled towards this direction (Murphy et al., 2019; Yu and Ngan, 2019). Nevertheless, studies on visitors' perceptions over robots have mostly employed a quantitative (Cha, 2020; Shin and Jeong, 2020; Ivanov and Webster, 2019), laboratory experimental (Tussyadiah and Park, 2018), or online review approach (such as Yu, 2020; Tung and Au, 2018). Despite the useful outcomes of such studies, researchers (such as Tung and $\mathrm{Au}, 2018$; Tung and Law, 2017) call for additional qualitative inquiry, such as in the form of interviews with guests so that additional - and in all likelihood, important information is emerged regarding the topic. A clear understanding of how tourists perceive the use of robots - particularly anthropomorphic in tourism, may equip organizations with the necessary knowledge of whether to adopt and how to implement such technology. Therefore, the aim of this study is to deliver a qualitative perspective on the investigation of visitors' perceptions on the usage of anthropomorphic robots in tourism and hospitality. 


\section{Literature Review}

Technology shapes society in different ways, such as the case of social practices in the form of education (Powers et al., 2018) and industries such as tourism (Tussyadiah et al., 2018). It has been advocated that technology determines the development of a society while technological changes influence society in terms of human relations. For instance, the use of robots within the hospitality domain has prompted some guests to interact as well as communicate with them (Tung and $\mathrm{Au}, 2018$ ). The notion that technology shapes society has been referred to as technological determinism. Researchers have attempted to examine the idea of technological determinism (Heilbroner, 1994). The term was originated from Veblen and elaborated by the philosopher Karl Marx. This position was supported by the notion that continuous and fast-changing technology changes human lives (Marx and Smith, 1994). There is adequate evidence to support that technology includes social aspects (Fleck and Howells, 2001) and causes societal changes such as the increased number of people using social media networks (Przepiorka and Blachnio, 2016). In fact, recent studies highlight the crucial role of technology in fundamentally changing how people live and connect with others (Kandampully et al., 2018). Indeed, technological changes within a society may shape peoples' roles, practices, perspectives and ways of living. For instance, once technology, such as in the form of robots, enters a social setting, it alters the roles of people, how people act in that situation or use context (De Graaf, 2016; Van Wynsberghe, 2012) or even the organizational culture (Xu et al., 2020). Technological determinism is not a constant phenomenon. That is, technology may influence people's lives and perceptions and alter the manner in which they view, perceive and demand additional, new and novel technology. For instance, robots in the hospitality industry may require customer interaction (Cha, 2020) and not simply act as providers of information for guests. Nonetheless, the manner in which technology shapes peoples' lives and perspectives may depend on the willingness of people to engage and interact with new technology. For instance, some individuals may be more keen than others to adopt and engage with new technology even to the extent of developing social relationships with robots. There is evidence to support that people may establish or seek to establish some form of social relationship with robots (Tung and $\mathrm{Au}, 2018$ ). This, despite the fact that robots are incapable of replacing human relationships that may be founded on love principles (Christou, 2018) and humans' sincere/genuine interactions (Shin and Jeong, 2020). In fact, De Graaf (2016) stresses that we need to secure human relationships instead of human-robot ones. Also, there is evidence that young people may easily accept and adopt to technological changes. Innovative products that limit the interaction with humans in the tourism industry have been easily adopted, used and accepted by young people who use technology extensively (Lu and Kandampully, 2016). Also, Millennial generation travelers are highly digitally perceptive (Litvin et al., 2018). Despite the fact that the older generation also accepts the evolution and the extensive use of technology in the tourism industry, they are found to be less willing to learn how to adopt new practices (Memarzadeh and Anand, 2020).

Indeed, technological advancement in the form of robots has dynamically entered our society, and more specifically the services industry (Tuomi et al., 2020). Robots may be defined as interfaces that interact in an autonomous way by offering services that would be, under other conditions, offered by humans (Wirtz and Zeithaml, 2018). They are used widely in places where they may alleviate the scarcity of labour - or simply replace labour - in order to perform simple or complex tasks, such as in restaurants, bars, kitchens, in housekeeping, front offices, airports and airlines (Zhu and Chang, 2020; Wirtz et al., 
2018; Wu and Cheng, 2018). Examples include security robots at airports, chef-robots in restaurants, robot luggage porters and butlers, robots as travel agents, robots as receptionists or in concierge services. Even so, the most usually approved usage of robots is perceived to be rather operational and functional, such as information provision and housekeeping (Ivanov and Webster, 2019). The study of Tuomi et al. (2020) revealed that robots support and even substitute hospitality employees. Studies (i.e. Bowen and Morsan, 2018; Kuo et al., 2017) note the strong and good potential of the hospitality industry to implement service robots.

Currently, start-ups and research institutes are working towards designing robots that resemble humans (Chung, 2018) and may be referred to as anthropomorphic robots. Such anthropomorphic cues embrace the shape of a robot that may resemble the human body, possess human features such as having a human-like voice and face, is able to move its head and other parts (i.e. arms and legs) and deliver expressions, such as smiling and laughing. Zhu and Chang (2020) make reference to robotic chefs in restaurants with humanoid/anthropomorphic hands. The Henn na (or "weird")- a hotel in Nagasaki, Japan, with processes handled by robots, opened in 2015 and featured different types of automated receptionists including a female android. Yeoman and Mars (2012) envisaged and presented a futuristic scenario of 2050 in which the famous red light district in Amsterdam could involve android prostitutes, who are not forced into slavery and who are clean of sexually transmitted infections.

The use of human-resembling robots may be perceived by people as adding value to the guest experience. Studies (i.e. Tung and $\mathrm{Au}, 2018$ ) stress the impact of robotic embodiment on consumer experiences. However, robots that resemble humans may create negative experiences for hospitality consumers by transmitting negative feelings to their users. This can be partially explained by the "weirdness" that people might experience when coming across robots that highly resemble humans. Mori (2012) stated that as a robot's appearance more resembles humans, people's response to the robot becomes positive up to a certain point, upon which this response changes into a negative one. That is, robots that poorly resemble humans result into uncanny feelings. However, as the appearance of the robot becomes less distinguishable from a human, then people's emotion become positive. The area between a hardly human and fully human is referred to as the "uncanny valley". Based on the findings of certain researchers (e.g. Stein and Ohler, 2017; Gray and Wegner, 2012), people may experience aversion if they come across highly emotion-sensitive technology within an era of high artificial intelligence and affective computing. The uncanny valley notion has not escaped criticism (Hanson et al., 2005) resting on the fact that eerie feelings may develop in the sight of any type of human resembling robot. Despite the imperative significance of emotional interactions and exchanges between service providers and tourists, the study of Strait et al. (2015) supported that people view highly resembling human robots as uncanny, thus they try to avoid them. Likewise, Yu (2020) revealed that perceptions of users towards humanlike robots tend to be negative. All the same, using robots in the operations as well as in other functions of the hospitality and tourism industry has become an issue of extensive research and discussion among scholars searching this industry and its current trends (Shin and Jeong, 2020; Zhu and Chang, 2020; Ivanov et al., 2019). Researchers have attempted to understand consumer perceptions of robots within the tourism context. In fact, tourists' perspectives and perceptions of experiences, activities or tourism products are of great importance for the success of the tourism industry (Tung and $\mathrm{Au}, 2018 ; \mathrm{Xu}, 2010$ ). Indeed, studies have examined robotics within the context of tourism (Ivanov et al., 2019) and the visitors' perceptions of their usage in the tourism/hospitality field. Despite this, there are current calls for a further investigation of the influence of the uncanny phenomenon within the context of restaurants/hospitality (Zhu and Chang, 2020). The 
answer to the question of whether visitors are willing to embrace a humanlike or anthropomorphic robot in the tourism and hospitality terrain remains rather elusive.

\section{Methodology}

The study used a qualitative methodological approach in order to delve deep into the issue of tourists' perceptions regarding robots in the tourism industry. Qualitative inquiry has made a noteworthy impact to tourism (Wilson and Hollinshead, 2015) especially in the case of examining tourists' perceptions (Zhao and Timothy, 2017). Hence, we felt that it was appropriate for gaining in-depth information in response to the study's scope. A mostly exploratory (Christou et al., 2019) and phenomenological approach was employed given that this approach allows in-depth investigations of complicated phenomena through individuals' experiences. That is, interviewees were prompted to share any personal experiences they had while viewing service robots or interacting with them. They were encouraged to share their views about robots (i.e. how they perceive them), and to divulge their thoughts and feelings on the possibility of coming across a robot that highly resembles a human being. Besides, phenomenological approaches are deemed suitable for the investigation of the nature of tourist experiences (Hayllar and Griffin, 2005) and the meanings that tourists assign to their experiences (Santos and Yan, 2010). The researchers aimed to extract rich information from informants through interviews hence adding value to the study's trustworthiness. In more detail, tourists who chose to spend their holidays in the international destination of Cyprus were approached by two researchers while they were holidaying. Despite the coronavirus outbreak that put tourism inflows to a standstill in early 2020, Cyprus is a destination that attracts millions of tourists from around the globe, who visit the country mainly for leisure purposes. The country is a pull for European travellers (such as from the UK) yet it also attracts visitors from other regions, such as Russia and Asia. The destination has a mature tourism industry, embracing chain hotels, various dining options, up-scale resorts, marinas, theme or archaeological parks and museums. Informants were purposely selected to ensure that the sample included varying views from both genders, different age-groups, from differing sectors/jobs, cultural backgrounds, and from people who have (and haven't) come into contact with robots (refer to Table 1). This approach delivered prominent characteristics of the sample in regard to understandings, opinions and views, hence establishing rigour (Ritchie et al., 2014).

\section{$<$ Please insert table 1, about here>}

Tourists who agreed to contribute to the study were interviewed based on qualitative inquiry principles (Seidman, 2019) with each interview lasting 20-35 minutes and in a commonly agreed place (such as at a quiet area of a park, or a hotel's lobby). Structured interviews were conducted with the informants. Open-ended questions were framed in order to address the study's aim and to allow topics to emerge naturally in terms of allowing informants to express their views and elaborate as much as possible. These questions were piloted and tested so that they were clear to interviewees (Brotherton, 2015) and shaped to assist the divulgence of deeper feelings and perceptions regarding the topic of anthropomorphic robots and their use in the tourism sector. That is, the pilot study results showed that informants were not referring to specific characteristics and functions that they would have preferred robots to possess. Hence, a specific question regarding this was added into the interview. The questions that guided the study are presented below: 
- Are you aware that robots are currently used in the tourism sector? [If so] can you provide any specific examples?

- Have you ever come across a "robot" and/or a robot specifically in the tourism or hospitality industry, such as in an airport, hotel or restaurant?

- [If yes to the above question] Did you interact with the robot? Can you elaborate? How would you describe your experience? Can you name any specific emotions you have felt? How did you feel?

- What is your opinion regarding the use of robots in services and specifically the tourism industry? Can you please elaborate?

- How would you feel if a robot looking like a human being was used in tourism services, such as a hotel setting? What do you believe would have been the impacts of such technology being used - towards you as a guest, the organization, or even society? [In case informants had not experienced an interaction with a robot - such as one that resembles a human being - then they were shown representative pictures or videos from interviewers. This would enable them to understand precisely what is meant by anthropomorphic robots and how these look and function].

- [The last question aimed to disclose personal feelings about the likelihood that robots are used more extensively in the tourism industry]: If robots were to be used more in tourism (such as in a travel agency, a cruise ship, an airplane or a hotel setting), how would you want these robots to look? What functions and characteristics would you have preferred they possessed? [Note: the question was framed to allow informants to describe how they would- personally like robots to look. Inevitably, this question was "forcing" informants who do not appreciate robots being used in tourism to express an opinion. Nonetheless, we felt that this would have allowed informants (in general) to consider that there is such a possibility and that they have a say in regard to how they would have liked these robots to appear/function].

The majority of the interviews were conducted in English, while all responses were carefully noted down in detail, verbatim. Some interviews were conducted in Greek and the responses were eventually translated and transcribed by a professional. The information collection phase came to an end when it was felt that new interviews were bringing in information that was simply reinforcing responses that had already been provided by other interviewees. That is, when saturation point was reached (Fusch and Ness, 2015). At this point, a total number of 78 interviews were retained in the study.

The information analysis process followed qualitative principles of analysis of the methodological approach set by Gioia (Gioia et al., 2013). More specifically, the analysis process involved three main phases. The first phase involved the assignment of conceptual codes to chunks of transcripts (that resulted from the above-mentioned general questions). This process involved two experienced researchers each reading carefully the replies of interviewees and delving deeper into each issue raised by informants. Secondly, these first-order codes were assembled into more manageable second-order groupings to enable understandings of peoples' perceptions, such as, for instance, their perceptions in regard to the use of anthropomorphic robots and their impact. Thirdly, a sense of the relation between the formed categories was practiced in distilling these to meaningful dimensions and deliverable outcomes. That is, the two researchers (together) discussed topics that emerged through the analysis of information and grouped these into specific themes. For example: Theme A: Awareness of robotic usage by the tourism industry in general; Theme B: Interaction with robots; Theme C: Opinions in 
response to the use of robots in fields related specifically to tourism and hospitality. Sub-themes were also created: positive opinions based on the personal experiences of guests, for example. The key findings of the study are presented below, while these are supported by representative quotations that were derived from informants.

\section{Results}

\section{Awareness and coming into contact with a robot}

In regard to awareness, most informants stated that they were aware of the fact that robots are used in the tourism industry, such as in a hotel's reception area. Others stated that they were aware that robots are used in services but weren't aware that they are used in the tourism sector. In response to the question on whether they had ever come across a robot, there were people who had come into contact with a robot and others who hadn't come into contact with a robot; both broad groups included people from both genders, different ages and cultural backgrounds:

I haven't come into contact with this kind of [anthropomorphic] robot in a hotel, but I got to know a robot up close called "Nao". "Nao" is a humanoid robot that performs some basic functions, mainly in education. My acquaintance with him was something new, revolutionary, innovative and also something nice (Mariam, 28).

As a result of further analysis, four main specific clusters of informants were identified:

i. First, a cluster of informants (51 in number) who hadn't come into contact with any type of robot - "I never had a chance to meet a robot during my holidays or elsewhere" (Leo, 41).

ii. Another cluster (consisting of 20 informants) said that they had come into contact with a robot, but not one that had human-like characteristics.

iii. A smaller cluster of informants (seven interviewees) said that they had come into contact with a robot that resembles human being - "I once had the chance to meet an anthropomorphic robot, 'Asimo' of Honda. It had artificial intelligence and it was autonomous" (Andrew, 33).

iv. The fourth cluster (consisting of six informants) included those people who had come into contact with a robot specifically in the hospitality or tourism industry.

The cluster that had come into contact and interacted with a robot in the tourism field expressed comments that revealed that their experience was rather positive.

\section{Opinions of having robots in tourism}

In general, the informants agreed with the fact that technological advancement in the tourism industry is something that is expected and rather anticipated. Both positive and negative comments were expressed in regard to the idea of having robots placed in hotels, airplanes and cruise ships. Such comments came from different age groups:

I wouldn't have liked it if there were robots instead of people in my vacation hotel. I wouldn't like the robots to serve me at all! It's scary and just the idea frightens me, it's 
anti-social and impersonal, because we wouldn't get in touch with other people... human communication is lost, the human contact is lost (Chelsea, 26).

Despite the above, more negative views were expressed by the cluster of informants who hadn't yet come into contact with any type of robot:

I don't trust robots yet to have the instinct to understand human needs... We are surrounded by a lot of services and things which are digital but I think hospitality is one of the few services which should still be done mostly by people (Michelle, $31)$.

Even informants who shared a positive opinion concur that the usage of robots should be rather limited and controlled: "I believe I wouldn't mind being served by a robot, but it would have bothered me if most or all hotel employees were robots" (Emily, 50).

\section{Perceptions of influences and impacts of robots}

The informants expressed various opinions in regard to the impacts that robot usage may have at a personal-guest, organizational and societal level.

\section{Personal level}

Informants who stated that they had come into contact with a robot expressed mainly positive reactions by using words such as "nice", "interesting", "informative", "amusement" and "amazement". Furthermore, informants expressed the view that the use of robots in the tourism field may add value to the guest experience to some extent, since robots "may provide information", "may be fast and efficient", may be "interesting to interact with" and bring a "technological new vibe" into the organization. In fact, this opinion was shared by both people who had come into or had not come into contact with robots. As Robby (25) enthusiastically claimed: "it would be a great experience for me!". Others (such as Raphaella, 27) stated that possible functional problems of robots could negatively affect the experience of customers. In more detail, those who stated that they had not come in contact with a robot shared an array of emotions and feelings on the possibility of coming across a robot in the tourism/hospitality industry. Some expressed positive emotions and feelings, with terms such as "enthusiasm", "curiosity" and "admiration."

I would definitely be impressed by the rapid development of technology, and at the same time feel curious about what is more to come and how the whole story will evolve (Demetri, 56).

Others (such as Sebastian, 25) communicated "indifference", "neutral feelings" and "apathy" while others expressed "skepticism" or a combination of positive and negative reactions.

I would feel weird at the beginning but if I see that the robot can serve me as a human would do, then I wouldn't really mind. I'm not the kind of person that cares much about communicating with people as long as I can be served effectively (Norman, 34). 
It would've surprised me, mainly the fact of what we have achieved as humanity. Also, I'd feel a little curious regarding its functionality, its intelligence, and how many things it can actually do, as well as curiosity about what the future holds for us, if such technology becomes more common. I think it would also scare me, as it would be creepy to see a humanoid type of machine look like, make movements and function as a human being! (Diamanto, 53).

However, most of them expressed negative feelings, mainly "fear", "anger" and even "sadness." Amongst others, the words "disappointment", "unpleasant", "impersonal", "weird", "fake" and "ridiculous" were mentioned.

At first I think I would get angry because I wouldn't like to talk to a robot, as the human communication which I find necessary in all human relationships, especially for the tourism industry, is completely gone...! Then, I would've reacted negatively by thinking that robots managed to deprive jobs from many people as it has no working hours, has no survival needs and does not need a salary. In general, I would be very sorry for such a development... (Agatha, 54).

\section{Organizational and societal level}

The majority of the interviewees acknowledge the benefits that may be created if tourism/hospitality organizations use robots, such as the fact that they may possibly minimize certain (human resource related) expenses, they may avoid/reduce mistakes, organizations may gain a competitive advantage, be in-line with technological advancements - "keep the level of service very high" (Dave, 26) - add value to the experience of their customers, or even "take it to the next level!" (Leo, 41). Others referred to the "need" for organizations to turn to such technology:

Nowadays we tend to communicate more through technology, such as through Facebook, and less in person. You can see this now with the coronavirus case anyway, there is less human interaction and more use of technology. Organizations are sort of forced to look at how they can implement and benefit from technology (Norman, 34).

Nonetheless, the vast majority of interviewees expressed opinions that support the view that the tourism industry should remain "humane", with informants stating that robots may cause the industry to "lose its [human] identity" (Bill, 52) and "lose the human interaction that is very important for this industry" (Dave, 26). As informants expressed, the industry is strongly based on notions such as "human interaction", "cross-cultural communication" and "emotional experiences". These, as they communicated, could be strongly undermined through the use of any type of robots.

For me it's very important to feel that the providers are being nice to me and care about me. I don't think that a robot, regardless of how much it looks like a real person or resembles a human, will be able to show affection... To be polite? yes. To show love? Not!... (Marta, 32). 
I would be impressed [referring to a possible interaction with a robot] with technological advancement and the level technology has reached. But I would also be sceptical and troubled by its development and the consequences it may have in human existence, progress and communication (Adam, 34).

Technology is advancing the industry and any other industry, so it is best to use it effectively and create an advantage over your competition... But it replaces the human element and this is scary since it reduces human interaction in services, and as a result we have less and less interaction with each other, first in a service social setting such as a hotel or an airport and later on in our lives in general (Bill, 52).

\section{Tourists' vision of the future}

The informants envisage an extensive use of robots in the future. Differing opinions were expressed in regard to their opinion about the implementation of such technology and this was found to be based on their initial perceptions. More specifically, those that expressed negative feelings regarding robots also expressed an antithetical position in regard to their implementation in the industry:

... it will never make an appeal to me! (Rex, 41)

... for sure I wouldn't like to be welcomed or served by a robot... As I explained earlier, the tourism industry is about human interaction, real face-to-face feedback, real experiences and not programmed ones... No matter how pleasant a robot looks or how ever polite it may be, it will never have real feelings and it will never be able to transfer real feelings to people! (Amina, 42).

Despite the above, the vast majority of interviewees stated that they would have preferred a robot to be anthropomorphic (rather than have any other shape) for it to grab their attention. As they explained, such kind of robot "would be something to remember" (Sebastian, 25) and "would have grabbed my attention" (Dave, 26). They would have perceived such robots as "closer to them" and more "empathetic". Even so, some shared a different opinion, that: "It shouldn't look like a human being" (Athinodoros, 66). However, some stated that not only should it resemble a human, but it should express emotions too.

I think that a robot in a hotel or an airplane wouldn't impress me anyway, but if there was one I'd rather it had a human appearance and human-like characteristics. Even so, I still feel that it could not replace the human factor (Moses, 33).

It should definitely be sophisticated and look like a human, move like a human, talk like a human being and express emotions like us... It should wear a uniform and look attractive so that it doesn't scare kids! (Norman, 34). 
Some others expressed a different view by stating that they would have preferred a robot to be distinguishable from humans, to look like a machine rather a human being, or even from a character taken from a fictional movie.

\section{Discussion and Conclusions}

\subsection{Conclusions}

The interviewees envisage that the tourism industry will make use of more robots in the future because it is "forced" to, as a result of technological advancement or due to other uncontrollable factors, such as the coronavirus outbreak. They generally acknowledge the contribution of robots in services and in the tourism/hospitality field by pointing out the benefits they may bring at a personal but also organizational level. Such advantages include the fact that robots are non-stop machines, they may deliver fast and consistent service and that they may elevate tourist experiences to a "different level". This seems to be in accord with the fact that technology - in the form of robots in this case - once it has entered a social environment, causes alternations (De Graaf, 2016; Van Wynsberghe, 2012), such as in regard to how people act and interact with a given situation. The informants envisage that the tourism industry will eventually turn to the use of further advanced technology in the form of robots for the delivery of its services. This outcome is in accord with claims that robots have dynamically entered the services industry (Tuomi et al., 2020) and that in the near future they will be extensively used in the hospitality industry (Bowen and Morosan, 2018). Within the realm of technological determination, it has been advocated that technology includes some aspect of the social (Fleck and Howells, 2001), that it changes how people live and connect with others (Kandampully et al., 2018) and influences society such as in terms of guests proactively seeking opportunities to interact with machines- robots (Tung and $\mathrm{Au}, 2018$ ). The results of this study point out that human-robot interaction may create positive feelings among guests, such as astonishment and surprise. This outcome supports previous claims that technology may enhance people's experiences (Tussyadiah et al., 2018). Of course, this does not imply that robots are carriers of only positive outcomes for visitors especially if they are associated with functional problems and limitations (Tung and $\mathrm{Au}$, 2018). Not only younger but also older tourists in this study expressed a willingness to interact with robots, reinforcing recent claims that the older generation is accepting the evolution and use of technology in the tourism industry (Memarzadeh and Anand, 2020). People from both genders, of different cultural backgrounds and various age groups expressed negative as well as positive feelings in response to robot usage in the industry. Even those who expressed enthusiasm for new technology and advancements in technology communicated "fears" that robots may replace human positions and have a negative effect on human relationships. Also, people who shared a rather negative perspective on how technology impacts and shapes our society acknowledged the positive contribution of robots. The informants expressed views that support robot usage in services, yet for rather functional operations, such as carrying tourists' luggage - as previous studies have revealed (Ivanov and Webster, 2019). In fact, the interviewees acknowledged that robots change traditional and typical practices or tourism organizations when it comes to service delivery being conducted by humans. Robots are widely used in the tourism sector (Cha, 2020; Wirtz et al., 2018; Wu and Cheng, 2018) and perform duties that would once have been performed by humans, such as allowing check in/out processes, preparing/delivering food, answering questions, providing directions and interacting with customers. Rather surprisingly, the majority concur that to grab their attention, a robot in the tourism industry should possess an anthropomorphic design, have human-like characteristics (such as a human-looking face), have a voice that resembles the human voice and 
express emotions like a human. Indeed, informants expressed favouritism towards an advanced anthropomorphic robot rather than a simple robot/machine of any other shape, if a robot was to be used in a tourism/hospitality setting. This favoritism towards an anthropomorphic robot contradicts claims that peoples' perceptions are rather negative when it comes to discussions about humanlike robots (Yu, 2020), hence try to avoid them (Strait et al., 2015).

Nonetheless, there are informants who expressed negative emotions, "weirdness" and aversion, even in the discussion of having any kind of robot (i.e. abstract or anthropomorphic) in a service setting. For instance, while referring to anthropomorphic robots, Rex (41) sharply claimed: "it will never make an appeal to me!" This expression of informants' aversion may be justified by the negative emotions (particularly "fear") that informants communicated in regard to the discourse of how fast technology is progressing and advancing in the modern world and the manner in which it can shape society (i.e. technological determinism- as discussed in the theoretical part of this paper). In fact, the study's findings point out that not all tourists are keen to interact and communicate with robots within the tourism and hospitality context. This outcome somewhat contradicts the view that people within a social context may establish or seek to establish a form of social relationship with new technology in the form of robots (Tung and $\mathrm{Au}, 2018$ ). It may be accepted that technology shapes social practices such as service delivery and social interaction within the service (hospitality) domain. As informants elaborated, robots are "untired", are able to deliver services, provide assistance, perform duties that would otherwise have been provided by humans, exhibit politeness and interact with guests, even to the extent of engaging into conversations with people. This reinforces to some extent the notion of technological determinism and the manner in which fast-changing technology changes human lives (Marx and Smith, 1994). However, based on the outcome of this study, (robot) technology cannot determine and enforce social relationships between humans and robots unless individuals actively seek to engage in such interaction and relationships. As this study has clearly revealed, tourists may discourage and abhor technological (robot) determinism, due to its overall negative impact on the tourism industry and society: "...we [will] have less and less interaction with each other, first in a service social setting such as a hotel or an airport and later on in our lives in general" (Bill, 52). The interviewees communicated their discontent, even "anger" with the possibility of jobs being taken away from employees because of robots. Others claimed that robot-human relationships cannot replace human-human relationships which have the privilege of being based on "genuine interactions and feelings" (Shin and Jeong, 2020; Christou, 2018) and the exchange of deep, meaningful, philosophical or spiritual conversations. Although the informants in general recognize the benefits of robot usage at a personal, organizational and industrial level, they are concerned about such outcomes. Indeed, technology shapes societies and the industries within, such as tourism (Tussyadiah et al., 2018), with service robots either supporting or substituting for hospitality employees (Tuomi, 2020). In this study, almost all interviewees expressed concerns regarding the impacts of robots towards the industry, the general services' sector and, subsequently, society. These concerns are expressed through skepticism and fears of human communication and interaction being deteriorated or lost as a result of robot usage. Of note is the fact that this view was shared by people of both genders, different cultural backgrounds and age groups.

The informants concur that robots may impact negatively on the anthropocentricity of any service organization that aims to deliver a welcoming, hospitable, warm and human-based emotional experience to its guests. In more detail, the informants expressed "fear" of the possibility of the tourism industry over-investing in robots. Their concerns are based on the fact that the industry will drop its 
"human identity", "human interaction", and "human communication". As the informants highlighted, robots are incapable of delivering important (mainly psychological) aspects that are of profound importance for tourists, such as engaging in deep and meaningful conversations with guests, delivering a "warm welcome", understanding deep "human needs", delivering true/genuine expressions such as a "smile", transferring "real feelings to people", or expressing genuine emotions, such as "love". As Neuhofer et al. (2014) correctly positioned the essence of the tourism industry is experiences while the channel of care from one human being to another is a core element of hospitality provision (Christou, 2018). Hence, this study supports that "human" experiences are the essence of the tourism and hospitality field, with the informants supporting that tourism - and more specifically the hospitality industry - should continue to possess a human-centered stance. As they stated, the use of robots could lead to a "loss in human interaction", as well as "deteriorate or damage human communication".

\subsection{Theoretical and practical implications}

The current study has responded to numerous recent and ongoing calls for further and in-depth examination of guests' views, perceptions, intentions and acceptance regarding the broad topic of robot endorsement in tourism and hospitality (Cha, 2020; Shin and Jeong, 2020; Law et al., 2019; Tung and $\mathrm{Au}, 2018)$. Also, this paper supplements previous studies by providing a holistic view of tourists' perceptions regarding (anthropomorphic) robots. The findings of this research aided in the construction of a matrix useful for researchers and practitioners since it demonstrates the perceptions of tourists on the use of robots according to their interaction (or not) with robots, present the characteristics and functional and inner elements of robots as perceived by tourists, and deliver a conceptual continuum of tourists' perceptions and concerns over the use of (anthropomorphic) robots. The conceptual matrix and diagrams can guide future studies (as presented in the section below regarding future research streams). In more detail, the informants expressed different perceptions - negative and positive - in regard to robots within the context of hospitality and tourism. This enabled us to construct a simplistic yet helpful matrix that presents this robot/guest interaction and perception nexus (refer to Figure 1).

\section{<Please insert Figure 1, about here>}

Through their responses, informants distinguished the functions that (anthropomorphic) robots are able and not able to perform. That is, interviewees made reference to the outside (surface) characteristics of robots such as a staff-uniform and other physical characteristics. Also, they referred to functional elements of robots such as their ability to move, have a human-like voice. They also referred to certain elements that could be described as "inner/deep" that could not be conveyed by robots, such as engaging in deep and meaningful discussions with guests, understanding or delivering genuine feelings and showing real care and concern towards guests. These characteristics, as elaborated by informants, enabled us to group them together and present them in a figure format (refer to Figure 2). Drawing on the perceptions of tourists, the surface, functional and deep elements constituting an anthropomorphic robot are presented.

\section{<Please insert Figure 2, about here >}

Additionally, and perhaps most importantly, a conceptual continuum of tourists' perceptions and concerns over the use of (anthropomorphic) robots is presented. The preferences and concerns of guests 
and the need for tourism organizations to intervene to allay such concerns are best illustrated in the following figure (refer to Figure 3).

\section{$<$ Please insert Figure 3, about here >}

Although there were those who shared an antithetical opinion, the informant in general concur that a robot in a tourism setting (such as a hotel) should have an anthropomorphic design. As they perceive it to be, compared to an ordinary robot/machine, a human-like robot is more interesting, exciting, eyeappealing and attractive. Therefore, tourism and hospitality stakeholders may look at the possibility of incorporating carefully designed (i.e. not scary) anthropomorphic robots in key service positions, such as in a hotel's lobby or in an airport. This type of robot may possess human-like characteristics (cues), as explained previously in the manuscript. For instance, such types of robot may take the role of a concierge, yet not replace them. It may be dressed in the hotel's uniform, sit behind a desk and provide information to guests, such as regarding the different types of restaurants that are available in hotel and the spa opening hours. This will give the opportunity to guests to interact with the robot, get "enthused" take pictures with it, and even share them on social networks. However, it should be stressed that this action (of robot usage) will not guarantee a positive holistic experience for all guests since there are those who do not appreciate the incorporation of such technology in hospitality. As noted previously, the thought of having robots replacing humans in the service provision domain creates for tourists a feeling of discomfort, insecurity, sadness and possibly anger. Thus, in the likelihood that tourism and hospitality organizations decide to invest in robots (particularly in service provision), then they may incorporate perhaps one anthropomorphic robot in their premise/setting under a condition of pivotal importance; They should be very cautious not to give the impression to guests that robots are replacing the human face of the organization. This is why only the number of one anthropomorphic robot is suggested. If the organization gives such an impression to their guests, then they are running the risk of being perceived as a non-anthropocentric organization. That is, one that does not truly care about its employees, its guests and their need for a welcoming, warm, caring, empathetic treatment, and the twoway interface (that is, human communication between the two parties).

\subsection{Limitations and Future Research}

This study did not point out differences based on gender, cultural background, occupation and age. Another limitation is the fact that not all informants have interacted with (anthropomorphic) robots. This did not allow us to explore deeper than we already have into the aspects of tourists' emotions and anthropomorphism itself. Although the examination of differing views from informants resulted in some interesting outcomes, it would have been interesting to explore in further detail the views of those who have come into contact with robots (i.e. less and highly human resembling robots). Additional qualitative and possibly exploratory studies are advisable in this direction. Furthermore, certain informants expressed a "weird" feeling of coming across and interacting with a robot, but this feeling of awkwardness was blended with feelings of surprise and astonishment rather than uncanniness, or feelings of aversion (Stein and Ohler, 2017; Gray and Wegner, 2012). Although beyond the scope of this study, the findings cannot support the notion of the "uncanny valley" (Mori, 2012). This is because informants did not interact with a wide spectrum of robots. For instance, there were informants who haven't interacted at all with robots and others who have interacted only with non-anthropomorphic ones. Despite this, five general research streams are proposed: 
Firstly, researchers may investigate and provide specific directions on how tourism and hospitality stakeholders may address people's concerns and "fears" that the industry may shift away from an anthropocentric one through the potential extensive use of robots.

Secondly, the three main elements of anthropomorphic robots and the conceptual continuum of tourists' perceptions and concerns that were previously covered, may guide future studies. For instance, it will be interesting to see how high-tech robot manufacturers address "deep and inner" elements of robots that could be used in the services, or more specifically the hospitality sector. Concurrently, researchers may investigate how people will respond to the "ability" of robots to convey deep notions such as care and empathy, especially within the services domain.

Thirdly, it will be interesting to examine how people will react to the possibility of state-of-the-art robots being used in tourism. However, for this to occur there must be a wide usage of such robots in the industry, and this may take years, considering the possible high costs of their purchase and implementation.

Fourthly, longitudinal studies may examine people's perceptions following the Covid-19 era to compare results with this study. It may be argued whether the need for less human (physical) interaction for health and safety purposes may lead people who are currently against robot endorsement in services to perceive their use as "necessary".

The fifth and last proposed research stream extends beyond the sphere of tourism to the general services sector. Researchers are advised to delve deeper into the issue of why there might be preference for anthropomorphic robots compared to abstract (non-human like) robots in the services' sector. What precisely underpins this preference? Is it because people are simply "fascinated" to interact with an anthropomorphic robot as explained by informants in this study? Or, is it because humans appreciate the interaction with others even if these others are not actually humans but machines that resemble humans instead? Or perhaps is this preference underpinned by the need of people to feel that they are being "heard" by a "human" instead of a machine (abstract robot)?

As a final note, robots (particularly those that resemble humans) may add value to the overall tourist experience. However, if tourism and hospitality organizations aim to come across as anthropocentric, then they should be cautious not to give the impression that human beings (i.e. employees) are being substituted by artificially intelligent high-tech machines. Thus, anthropomorphism should not replace anthropocentrism. Robots may be able to perform astonishing actions, mimic human voices, smiles and even emotional reactions. Yet they are incapable of transferring heart-driven smiles, providing psychological warmth, hospitality, or expressing care, concern and empathy towards guests.

\section{References}

Bowen, J., and Morosan, C. (2018). "Beware hospitality industry: the robots are coming", Worldwide Hospitality and Tourism Themes, Vol. 10 No.6, pp. 726-733.

Brotherton, B. (2015). Researching hospitality and tourism, $2^{\text {nd }}$ ed. SAGE Publications. 
Cha, S.S. (2020). "Customers' intention to use robot-serviced restaurants in Korea: relationship of coolness and MCI factors", International Journal of Contemporary Hospitality Management, Vol. 32 No. 9, pp. 2947-2968.

Christou, P. A. (2018). "Exploring agape: Tourists on the island of love", Tourism Management, Vol. 68, pp.13-22.

Christou, P., Hadjielias, E., and Farmaki, A. (2019). "Reconnaissance of philanthropy", Annals of Tourism Research, Vo.78, 102749.

Chung, S. (2018). "Meet Sophia: The robot who laughs, smiles and frowns just like us", CNN. Available online: https://edition.cnn.com/style/article/sophia-robot-artificial-intelligence-smartcreativity/index.html. (accessed: June 2020).

Cuthbertson, A. (2020). "Coronavirus: 'Little peanut' robot delivers food to people in quarantine in China", Independent. Available online: https://www.independent.co.uk/life-style/gadgets-andtech/news/coronavirus-quarantine-robot-china-little-peanut-food-delivery-a9308166.html.

(accessed: June 2020).

De Graaf, M. M. (2016). “An ethical evaluation of human-robot relationships”, International journal of social robotics, Vol. 8 No.4, pp.589-598.

Fleck, J., and Howells, J. (2001). "Technology, the technology complex and the paradox of technological determinism", Technology Analysis \& Strategic Management, Vol.13 No.4, pp.523531.

Fusch, P. I., and Ness, L. R. (2015). "Are we there yet? Data saturation in qualitative research", The Qualitative Report, Vol. 20 No. 9, 1408.

Gioia, D. A., Corley, K. G., and Hamilton, A. L. (2013). "Seeking qualitative rigor in inductive research: Notes on the Gioia methodology",. Organizational research methods, Vol.16 No. 1, pp. $15-31$.

Gray, K., and Wegner, D. M. (2012). "Feeling robots and human zombies: Mind perception and the uncanny valley", Cognition. Vol. 125 No.1, pp. 125-130.

Hanson, D., Olney, A., Pereira, I. A., and Zielke, M. (2005). Upending the Uncanny Valley. Proceedings of the National Conference on Artificial Intelligence. 20, pp. 1728-1729.

Hayllar, B., and Griffin, T. (2005). “The precinct experience: a phenomenological approach”, Tourism Management, Vol. 26, No. 4, pp. 517-528.

Heilbroner, R. (1994). Technological determinism revisited. Does technology drive history, pp. 67-78.

Huang, Y. C., Backman, K. F., Backman, S. J., and Chang, L. L. (2016). "Exploring the implications of virtual reality technology in tourism marketing: An integrated research framework", International Journal of Tourism Research, Vol. 18, No. 2, pp. 116-128. 
Ivanov, S., Gretzel, U., Berezina, K., Sigala, M., and Webster, C. (2019). "Progress on robotics in hospitality and tourism: a review of the literature", Journal of Hospitality and Tourism Technology, Vol. 10 No.4, 489-521.

Ivanov, S., and Webster, C. (2019), "Perceived appropriateness and intention to use service robots in tourism". In: Information and Communication Technologies in Tourism 2019 (237-248). Springer, Cham.

Kandampully, J., Zhang, T. and Jaakkola, E. (2018). "Customer experience management in hospitality: A literature synthesis, new understanding and research agenda", International Journal of Contemporary Hospitality Management, Vol. 30 No. 1, pp. 21-56.

Kuo, C. M., Chen, L. C., and Tseng, C. Y. (2017). "Investigating an innovative service with hospitality robots", International Journal of Contemporary Hospitality Management, Vol. 29 No. 5, pp. 13051321.

Law, R., Fong, D.K.C., Chan, I.C.C. and Fong, L.H.N. (2018). "Systematic review of hospitality CRM research", International Journal of Contemporary Hospitality Management, Vol. 30 No. 3, pp. 1686-1704.

Law, R., Leung, D. and Chan, I.C.C. (2019). "Progression and development of information and communication technology research in hospitality and tourism: A state-of-the-art review", International Journal of Contemporary Hospitality Management, Vol. 32 No. 2, pp. 511-534.

Litvin, S.W., Goldsmith, R.E. and Pan, B. (2018). "A retrospective view of electronic word-of-mouth in hospitality and tourism management", International Journal of Contemporary Hospitality Management, Vol. 30 No. 1, pp. 313-325.

Lu, C., and Kandampully, J. (2016). "What drives customers to use access-based sharing options in the hospitality industry?”, Research in Hospitality Management, Vol. 6 No.2, pp. 119-126.

Marx, L. and Smith, M.R. (1994). "Does technology drive history? The dilemma of technological determinism”. MIT Press.

Memarzadeh, F., and Anand, S. (2020). "Hotel Guests' Perceptions of Green Technology Applications, and Practices in the Hotel Industry", International Journal of Tourism and Hospitality Management in the Digital Age, Vol. 4 No.1, pp. 1-9.

Mori, M (2012) [1970]. “The uncanny valley”. IEEE Robotics \& Automation Magazine, Vol., 19 No. 2 , pp. 98-100.

Murphy, J., Gretzel, U., and Pesonen, J. (2019). "Marketing robot services in hospitality and tourism: the role of anthropomorphism”, Journal of Travel \& Tourism Marketing, Vol. 36 No. 7, pp. 784795.

Neuhofer, B., Buhalis, D., and Ladkin, A. (2014). "A typology of technology-enhanced tourism experiences”, International Journal of Tourism Research, Vol. 16 No. 4, pp. 340-350. 
Okumus, F. (2013). "Facilitating knowledge management through information technology in hospitality organizations", Journal of Hospitality and Tourism Technology, Vol. 4 No. 1, pp. 6480.

Powers, J. R., Musgrove, A. T., and Lowe, J. A. (2018). "Technology Shaping Education in Rural Communities". In Handbook of Research on Human Development in the Digital Age, pp. 184-204. IGI Global.

Przepiorka, A., and Blachnio, A. (2016). "Time perspective in Internet and Facebook addiction", Computers in Human Behavior, Vol.60, pp. 13-18.

Ritchie, J. Lewis, J., Nicholls, C. and Ormston, R. (2014). Qualitative Research Practice, $4^{\text {th }}$ ed., Los Angeles: Sage.

Santos, C. A., and Yan, G. (2010). "Genealogical tourism: A phenomenological examination", Journal of Travel Research, Vol. 49 No. 1, pp. 56-67.

Seidman, I. (2019). Interviewing as qualitative research. $5^{\text {th }}$ ed. New York: Teachers College Press.

Shin, H.H. and Jeong, M. (2020), "Guests' perceptions of robot concierge and their adoption intentions", International Journal of Contemporary Hospitality Management, Vol. 32 No. 8, pp. 2613-2633.

Strait, M., Vujovic, L., Floerke, V., Scheutz, M., and Urry, H. (2015). Too much humanness for human-robot interaction: exposure to highly humanlike robots elicits aversive responding in observers. In Proceedings of the 33rd annual ACM conference on human factors in computing systems, 3593-3602.

Stein, J-P, and Ohler, P. (2017). "Venturing into the uncanny valley of mind-The influence of mind attribution on the acceptance of human-like characters in a virtual reality setting". Cognition. Vol. 160, pp. 43-50.

Tung, V. W. S., and Au, N. (2018). "Exploring customer experiences with robotics in hospitality", International Journal of Contemporary Hospitality Management, Vol. 30 No. 7, pp. 2680-2697.

Tung, V. W. S., and Law, R. (2017). "The potential for tourism and hospitality experience research in human-robot interactions", International Journal of Contemporary Hospitality Management, Vo. 29 No. 10, pp. 2498-2513.

Tuomi, A., Tussyadiah, I. P., and Stienmetz, J. (2020). “Applications and Implications of Service Robots in Hospitality”, Cornell Hospitality Quarterly, 1938965520923961.

Tussyadiah, I. P., Jung, T. H., and tom Dieck, M. C. (2018). "Embodiment of wearable augmented reality technology in tourism experiences", Journal of Travel Research, Vol. 57, No. 5, pp. 597611.

Tussyadiah, I. P., and Park, S. (2018). Consumer evaluation of hotel service robots. In Information and communication technologies in tourism 2018 (308-320). Springer, Cham. 
Van Wynsberghe, A.M. (2012) "Designing robots for care: care centered value-sensitive design", Sci Eng Ethics, 19:40-433

Wilson, E., and Hollinshead, K. (2015). "Qualitative tourism research: Opportunities in the emergent soft sciences", Annals of Tourism Research, vol. 54, pp. 30-47.

Wirtz, J. and Zeithaml, V. (2018). "Cost-effective service excellence", Journal of the Academy of Marketing Science, Vol. 46 No. 1, pp. 59-80.

Wirtz, J., Patterson, P.G., Kunz, W.H., Gruber, T., Lu, V.N and Paluch, S. (2018). "Brave new world: Service robots in the frontline", Journal of Service Management, Vol. 29 No. 5, pp. 907-931.

Wu, H.C. and Cheng C.C. (2018). "What drives experiential loyalty toward smart restaurants? The case study of KFC in Beijing”, Journal of Hospitality Marketing \& Management, Vol. 27 No. 2, pp. $151-177$

Xu, J. B. (2010). “Perceptions of tourism products”, Tourism Management, Vol. 31 No. 5, pp. 607-610.

Xu, S., Stienmetz, J. and Ashton, M. (2020). "How will service robots redefine leadership in hotel management? A Delphi approach", International Journal of Contemporary Hospitality Management, Vol. 32 No. 6, pp. 2217-2237.

Yeoman, I., and Mars, M. (2012). "Robots, men and sex tourism”, Futures, Vol. 44, No. 4, pp. 365371.

Yu, C. E. (2020). "Humanlike robots as employees in the hotel industry: Thematic content analysis of online reviews", Journal of Hospitality Marketing \& Management, Vol. 29 No.1, pp. 22-38.

Yu, C. E., and Ngan, H. F. B. (2019). "The power of head tilts: Gender and cultural differences of perceived human vs human-like robot smile in service”, Tourism Review, Vol. 74 No. 3, pp. 428442.

Zhao, S. (N). and Timothy, D.J. (2017). "Tourists' consumption and perceptions of red heritage", Annals of Tourism Research, Vol. 63, pp. 97-111.

Zhu, D.H. and Chang, Y.P. (2020). "Robot with humanoid hands cooks food better? Effect of robotic chef anthropomorphism on food quality prediction", International Journal of Contemporary Hospitality Management, Vol. 32 No. 3, pp. 1367-1383. 